\title{
Characteristics of Acute Appendicitis before and during the COVID-19 Pandemic: Single Center Experience
}

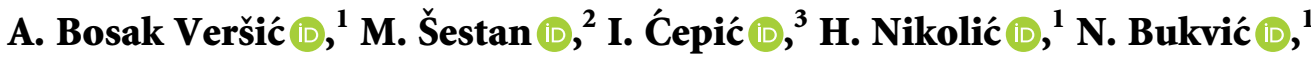 \\ S. Sršen Medančićc $\left(\mathbb{D},{ }^{1}\right.$ D. Hasandić $\left(\mathbb{D},{ }^{1}\right.$ and M. Zelićc $\mathbb{D}^{3}$ \\ ${ }^{1}$ Pediatric Surgery Department, University Hospital Rijeka, Rijeka 51000, Croatia \\ ${ }^{2}$ Medical Faculty, University Hospital Rijeka, Rijeka 51000, Croatia \\ ${ }^{3}$ Surgery Department, University Hospital Rijeka, Rijeka 5100, Croatia \\ Correspondence should be addressed to A. Bosak Veršić; anabosak@yahoo.com
}

Received 26 November 2021; Accepted 28 January 2022; Published 24 February 2022

Academic Editor: Roberto Cirocchi

Copyright (c) 2022 A. Bosak Veršić et al. This is an open access article distributed under the Creative Commons Attribution License, which permits unrestricted use, distribution, and reproduction in any medium, provided the original work is properly cited.

\begin{abstract}
The aim of the study was to investigate whether the COVID-19 pandemic caused an increased incidence of complicated appendicitis due to the late presentation when compared to the pre-COVID-19 period. Summary Background Data. Acute appendicitis is one of the most common surgical emergencies. During the coronavirus-19 (COVID-19) pandemic, there has been a reported delay in the presentation of some urgencies to the emergency hospital departments. Methods. A total of 427 patients who underwent surgical treatment due to suspected acute appendicitis from June 2019 to November 2020 were retrospectively included in this study. The patients were divided into two groups: the first (pre-COVID-19) group consisted of patients who had surgery before the onset of COVID-19 pandemic $(n=240)$, while the second (COVID-19) group consisted of those who were operated during the COVID-19 pandemic $(n=187)$. The primary outcome of the study was to compare the incidence of perforated appendicitis before and during the onset of COVID-19. Results. Overall, 84 patients (19.67\%) were diagnosed with perforated appendicitis. We found a weak significance $(p=0.085)$ in the rate of perforated appendicitis between the pre-COVID$19(17.08 \%)$ and the COVID-19 era (22.99\%). Conclusions. We did not observe any significant difference in the complications of acute appendicitis before and during the COVID-19 pandemic in a university hospital in Rijeka. An emergent medical care should always be accessible.
\end{abstract}

\section{Introduction}

At the end of 2019, a new coronavirus was identified as the cause of a cluster of pneumonia cases in Wuhan, China. It rapidly spreads, resulting in an epidemic throughout China, followed by an increase in the number of cases in countries around the world. In February 2020, the World Health Organization (WHO) designated the disease COVID-19, which stands for coronavirus disease 2019 [1, 2]. Many countries struggled to stave off the rapid spread of COVID19 by implementing different strategies. In most countries, including Croatia, authorities have instructed the public to stay at home and to avoid unnecessary socializing. In our hospital, a significant decrease in the number of emergency department (ED) examinations has been noted. However, urgent medical cases have continued to appear along the current outbreak, and their diagnosis needs to be made appropriately. Delayed diagnosis and treatment of these conditions may lead to a significant morbidity that may outweigh the harm caused by COVID-19 infection [3]. Acute appendicitis is one of the most common abdominal surgical emergencies in general with a 7\% lifetime risk [4-7]. Eventhough antibiotics have been described as a type of therapy for uncomplicated appendicitis, surgery still remains the preferable treatment modality [8]. Early diagnosis of appendicitis and consequent appropriate surgical treatment is important as it may prevent complications such as appendix perforation, abscess formation, and other postoperative complications including death [9]. During the COVID-19 pandemic, it is expected that more patients will 
seek out medical care in the later stage of the disease along with significant complications $[2,10]$. The aim of this study is to investigate the characteristics and management of patients with acute appendicitis in our hospital during the first wave of COVID-19 pandemic compared to the preCOVID-19 period.

\section{Patients and Methods}

We performed a retrospective monocentre observational study that included adult and pediatric patients surgically treated due to suspected acute appendicitis in the period from 1st of June 2019 to 31st of December 2020. The patients were divided into two groups: those treated in the preCOVID-19 era and the ones treated during the COVID-19 era. We included all patients $2-86$ years old who were referred to our surgical teams in a university hospital in Rijeka, Croatia, with suspected appendicitis. Initially, a total of 456 patients were included in the study (Figure 1). The data were collected from the hospital database. 14 patients who underwent interval appendectomy (due to chronic appendicitis) were excluded from the study. Additionally, 3 patients who were diagnosed with appendicular malignancies were also excluded from the study, as well as 12 patients with insufficient data available. Approval was obtained from the ethics committee at the hospital. In regard to treatment, patients were included if they were treated surgically with laparoscopic or open appendectomy. Data extracted from patients' notes included demographic and clinicopathological variables, duration of symptoms upon presentation in the $\mathrm{ED}$, and postoperative length of stay. Intraoperative findings were recorded and classified as acute appendicitis if gross acute inflammation of the appendix was seen. We divided the diagnosis into 3 groups: normal appendicitis, uncomplicated appendicitis, and perforated appendicitis. The primary outcome of the study was to compare the incidence of perforated appendicitis before and during the onset of COVID-19. In order to assess these outcomes, the cohort was allocated into two groups. In the first group, preCOVID-19 patients were hospitalized in the period from $1^{\text {st }}$ of June 2019 to $10^{\text {th }}$ of March 2020. In the second group, COVID-19 era patients were hospitalized in the period from $11^{\text {th }}$ of March 2020 to $31^{\text {st }}$ of December 2020.

2.1. Statistical Analysis. Statistical analyses were performed using MedCalc for Windows, version 19.4 (MedCalc Software, Ostend, Belgium). Patient cohorts were compared using chi-square, Student's $t$-test, and Mann-Whitney $U$ tests where appropriate. A $p$ value of $<0.05$ was considered significant.

\section{Results}

Within the two periods of this study, a total of 427 patients were included, 240 in the pre-COVID-19 era and 187 in the COVID-19 era. We noted a $22 \%$ drop in the number of appendicitis patients treated in the COVID-19 era when compared to the pre-COVID-19 period. Baseline demographic data of all patients are given in Table 1. There were
104 pediatric and 323 adult patients treated. The median age of the entire population treated was 31 years. Male patients predominated (53.63\%). There were no significant demographic differences across time periods.

Clinical characteristics are given in Table 2.

Median length of duration of symptoms upon presentation was 1 day with no difference between the two groups observed. There was no significant difference in the surgical treatment modality (open vs. laparoscopic) between the two periods $(p=0.368)$. Overall, 84 patients $(19.67 \%)$ were diagnosed with perforated appendicitis. In the COVID-19 era, there was an incidence of $22.99 \%$ of perforated appendicitis and $17.08 \%$ in the pre-COVID-19 era $(p=0.085)$ which is weakly significant. Our negative appendectomy rate overall and in pre-COVID-19 and COVID-19 era was 11.24\%, $13.75 \%$, and $8.02 \%$, respectively. Duration of symptoms and length of hospitalization were longer in patients with perforated appendicitis (overall). The average duration of symptoms in all patients was 24 hours; however, when observing perforated appendicitis only, it was 48 hours. Radiologic investigations (US and CT) are used more frequently in patients with more severe clinical presentation $(p=0.006$, $p<0.001)$. We did not find any increase in radiologic investigations between the pre-COVID-19 and COVID-19 era.

The duration of hospitalization on average was 5 days, and in those with perforation, it was 7 days. We did not find a significant difference in the duration of symptoms $(p=0.065)$ and in duration of hospitalization $(p=0.990)$ before the COVID-19 and during the COVID-19 era. The duration of hospitalization, in perforated appendicitis only, was shorter in the COVID-19 era $(p=0.025)$. We noticed that there was a significantly higher percentage of antibiotics being used when observing appendicitis patients in the COVID-19 era $(p<0.001)$ as well as when observing nonappendicitis cases in the same period. We did not find any increase in radiologic investigations between the preCOVID-19 and COVID-19 era.

\section{Discussion}

According to our knowledge, this is the only study analyzing appendicitis management during the COVID-19 pandemic in Croatia.

The main results of our study showed a weakly significant higher rate of complicated appendicitis during the COVID-19 era when compared to the pre-COVID-19 period. There were not any demographic differences between the time periods. The time between the onset of symptoms and presentation at the emergency hospital department did not prolong in the COVID-19 era. There was no change in a surgical management modality and length of hospital stay in the two time periods observed.

During the COVID-19 pandemic, most of the medical centers worldwide postponed or canceled regular elective procedures. The same was in Croatia. Surgical procedures were limited to urgent surgical, oncology, or trauma cases. The aim was to minimize unnecessary work load in the healthcare system and reduce emergency department patient encounters [11-13]. Furthermore, a significant 


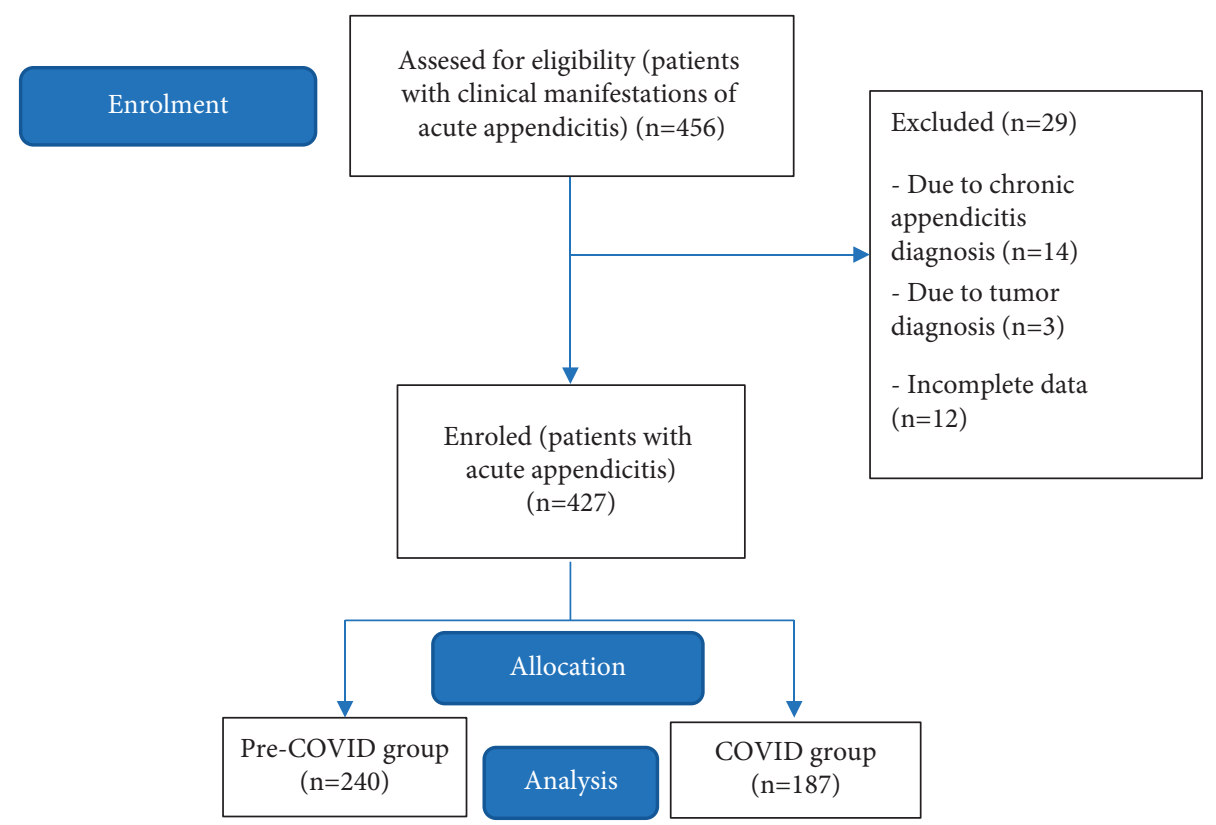

FIGURE 1: Flowchart of patient inclusion. A total of 456 patients were included in the study, 240 in the pre-COVID-19 group and 187 in the COVID-19 group.

TABLE 1: Comparison of demographic data between the two groups.

\begin{tabular}{|c|c|c|c|c|}
\hline Variable & $\begin{array}{c}\text { Total } \\
N=427\end{array}$ & $\begin{array}{l}\text { Pre-COVID group } \\
\qquad N=240\end{array}$ & $\begin{array}{c}\text { COVID group } \\
\quad N=187\end{array}$ & $P$ value \\
\hline Age, median (range) & $31(2-92)$ & $29(2-86)$ & $33(4-92)$ & 0.061 \\
\hline \multicolumn{5}{|l|}{ Sex, $n(\%)$} \\
\hline Male & $229(53.63)$ & $126(52.50)$ & $103(55.08)$ & 0.596 \\
\hline Female & $198(46.37)$ & $114(47.50)$ & $84(44.92)$ & 0.596 \\
\hline
\end{tabular}

There was no difference in the demographic characteristics between the two groups.

TABLE 2: Treatment characteristics of the patients in the two groups observed.

\begin{tabular}{|c|c|c|c|c|}
\hline Variable & $\begin{array}{c}\text { Total } \\
N=427\end{array}$ & $\begin{array}{l}\text { Pre-COVID group } \\
\qquad N=240 \\
\end{array}$ & $\begin{array}{c}\text { COVID group } \\
\quad N=187 \\
\end{array}$ & $P$ value \\
\hline Duration of symptoms, hours, self-reported & $24(1-240)$ & $24(3-168)$ & $24(1-240)$ & 0.065 \\
\hline $\begin{array}{l}\text { Treatment modality, } n(\%) \\
\text { Open appendectomy } \\
\text { Laparoscopic appendectomy }\end{array}$ & $\begin{array}{l}104(24.36) \\
323(75.64) \\
\end{array}$ & $\begin{array}{c}54(22.50) \\
186(77.50) \\
\end{array}$ & $\begin{array}{c}50(26.74) \\
137(73.26) \\
\end{array}$ & 0.368 \\
\hline Administration of antibiotics, $n(\%)$ & $332(77.75)$ & $160(66.67)$ & $172(91.98)$ & $<0.001$ \\
\hline $\begin{array}{l}\text { Grade of appendicitis, } n(\%) \\
\text { Normal appendix } \\
\text { Uncomplicated appendicitis } \\
\text { Complicated appendicitis }\end{array}$ & $\begin{array}{c}48(11.24) \\
295(69.09) \\
84(19.67) \\
\end{array}$ & $\begin{array}{c}33(13.75) \\
166(69.17) \\
41(17.08)\end{array}$ & $\begin{array}{c}15(8.02) \\
129(68.98) \\
43(22.99) \\
\end{array}$ & $\begin{array}{l}0.085 \\
0.085 \\
0.085\end{array}$ \\
\hline $\begin{array}{l}\text { Postoperative peritoneal drain, } n(\%) \\
\text { Length of admission (days) }\end{array}$ & $\begin{array}{c}152(35.60) \\
5(2-33) \\
\end{array}$ & $\begin{array}{c}78(32.50) \\
5(2-33) \\
\end{array}$ & $\begin{array}{c}74(39.57) \\
5(3-32) \\
\end{array}$ & $\begin{array}{l}0.130 \\
0.990 \\
\end{array}$ \\
\hline $\begin{array}{l}\text { Final diagnostic imaging, } n(\%) \\
\text { Ultrasound } \\
\text { CT }\end{array}$ & $\begin{array}{c}137(32.08) \\
39(9.13)\end{array}$ & $\begin{array}{l}80(33.33) \\
24(10.00)\end{array}$ & $\begin{array}{c}57(30.48) \\
15(8.02)\end{array}$ & $\begin{array}{l}0.531 \\
0.481\end{array}$ \\
\hline
\end{tabular}

We did not notice any significant differences in the duration of symptoms between the pre-COVID-19 and COVID-19 groups. There was no change in the representation of operational techniques. We noticed higher rate of antibiotics administration during the COVID-19 period. The incidence of complicated appendicitis was not higher in the COVID-19 period. Also, the length of hospital stay did not change during the COVID-19 era. Imaging techniques were equally represented before and in the COVID-19 era.

increase in delayed medical treatment for various emergencies during the COVID-19 pandemic period has been noted $[13,14]$. Several recent studies of acute appendicitis during COVID-19 pandemic clearly show that staying at home due to public health safety orders negatively impacted children and adults who developed appendicitis 
$[6,10,13-15]$. During the COVID-19 pandemic, an increased rate of perforated appendicitis, compared to the pre-COVID-19 period, was reported in several published studies $[6,10,14,16-18]$. Moreover, it has been noted that patients with perforated appendicitis have had an increased rate of complications and length of hospital stay $[3,11,12,17,19,20]$. COVID-19 is characterized by an unpredictable disease course, ranging from asymptomatic infections to severe and life-threatening situations. Pan et al. observed that $50.5 \%$ of patients infected with COVID-19 reported gastrointestinal symptoms along with the presence of respiratory symptoms [21]. Therefore, the diagnosis of acute appendicitis may be challenging during the COVID-19 pandemic. Appendectomy is the gold standard of treatment for acute appendicitis. However, recent studies suggest that conservative management with intravenous antibiotics can be used as an alternative $[8,22]$. On the other hand, appendectomy remains the most effective and safe treatment option and provides curative treatment without recurrence risk. In this study, we have shown that in our hospital, the number of patients presented to the ED with clinical signs of acute appendicitis decreased during the time when the number of COVID-19 cases started to increase. It is possible that patients choose not to present to the ED. The decision might have been influenced by the aggressive national policy of social isolation in Croatia. Furthermore, there might have been an element of patient's concern about patient-to-patient SARS-CoV-19 airborne transmission in the ED.

There was no significant difference between the two observed groups in terms of length of preoperative symptoms or type of surgery, need for postoperative peritoneal drainage, or the distribution of complicated versus uncomplicated appendicitis.

There are several possibilities that could explain this trend. This could be backed-up by some reports describing a successful resolution of mild appendicitis treated symptomatically by patients at their own private home settings $[23,24]$. Additionally, some patients might have been treated by primary healthcare practitioners. The reason for no significant increase in complicated appendicitis might also lie in the fact that the treatment in our hospital is covered by national health insurance and access was never limited, denied, or postponed by COVID-19 testing.

Similar to our results, there are studies done in Italy, Turkey, Israel, and Germany. Although the fear of the COVID19 pandemic resulted in a delayed diagnosis of some serious pediatric and adult diseases, an increase in the prevalence and severity of acute appendicitis was not demonstrated even in most COVID-19 affected areas in Italy [11, 25]. German authors also noted an overall drop in the number of uncomplicated appendicitis cases and no change in the rates of perforated appendicitis [24]. A study from Israeli tertiary center reported the same incidence of perforated appendicitis before and after the onset of the pandemic [26].

Similarly, no increase in the diagnosis of perforated appendicitis during the pandemic period was obtained by Turkish authors [27].
Some studies, on the contrary, have reported different results. In Japan, the authors found a delay in presentation for acute appendicitis with a higher incidence of perforation [28]. Higher rates of perforated appendicitis were also described by several American authors [15,29], as well as in the study from a poor area in Nepal [30].

Our negative appendectomy rates observed correlate with those described in the literature [7].

The common conclusion of all authors reporting a higher incidence of complicated appendicitis was disruption of continuous medical care due to public healthcare crisis.

We think that the reason for our results was that the system was as accessible during the pandemic as it was before the period, and there were fewer "nonurgent" cases going throughout emergency departments. In addition, at the time, our system was not preoccupied with COVID-19 patients.

The main limitations of the study are the retrospective character of the study and the fact that it is a single centre experience. However, since the pandemic still continues, an expanded study that would include all main centers in the country will be considered. Furthermore, we limited the period of the study to 9 months pre and post-COVID, since at the time, it was not possible to predict the duration of the situation.

\section{Conclusion}

We did not observe any significant difference in the rate of complications of acute appendicitis before and during the COVID-19 pandemic in a university hospital in Rijeka. We think we obtained this result because, despite the appeals not to go to the hospital if not necessary, emergency healthcare still remained as accessible as before the COVID-19 pandemic. Additionally, the reason might be that the pandemic did not affect our region at the time as severely as it did some other countries.

\section{Data Availability}

The data used to support the findings of this study are available from the corresponding author upon request.

\section{Ethical Approval}

The study protocol was approved by the local ethics review board (ref. nr. 003-05/21-1/29).

\section{Conflicts of Interest}

The authors declare that they have no conflicts of interest.

\section{Authors' Contributions}

ABV designed the study and obtained ethics approval. MS, IC, and DH collected the data. ABV and MZ analyzed the data. ABV, MS, and SSM drafted the manuscript. HN and $\mathrm{NB}$ revised the manuscript. ABV took responsibility for the study as a whole. All authors contributed substantially to its final revision. 


\section{Supplementary Materials}

Strobe checklist: checklist of the items in this cohort study. (Supplementary Materials).

\section{References}

[1] D. Cucinotta and M. Vanelli, "WHO declares COVID-19 a pandemic," Acta Bio-Medica: Atenei Parmensis, vol. 91, pp. 157-160, 2020.

[2] A. S. Fauci, H. C. Lane, and R. R. Redfield, "Covid-19-navigating the uncharted," New England Journal of Medicine, vol. 382 , no. 13, pp. 1268-1269, 2020.

[3] S. J. Lange, M. D. Ritchey, A. B. Goodman et al., "Potential indirect effects of the COVID-19 pandemic on use of emergency departments for acute life-threatening conditionsUnited States, January-May 2020," American Journal of Transplantation, vol. 20, no. 9, pp. 2612-2617, 2020.

[4] M. J. Snyder, M. Guthrie, and S. Cagle, "Acute appendicitis: efficient diagnosis and management," American Family Physician, vol. 98, no. 1, pp. 25-33, 2018.

[5] M. N. H. Khan, A. B. Jamal, A. Faraz et al., "Management of acute appendicitis during the COVID-19 pandemic is significantly different: a retrospective single UK hospital study," Journal of Multidisciplinary Healthcare, vol. 14, pp. 24152420, 2021.

[6] D. Wichmann, U. Schweizer, D. Wulff et al., "Incidence of perforated appendicitis during the COVID-19 pandemic: lessons to Be considered in the second wave," Journal of Gastrointestinal Surgery, vol. 25, no. 9, pp. 2404-2406, 2021.

[7] A. Bosak Versic, N. Glavan, N. Bukvic, Z. Tomasic, and H. Nikolic, "Does elevated urinary 5-hydroxyindole acetic acid level predict acute appendicitis in children?" Emergency Medicine Journal, vol. 33, no. 12, pp. 848-852, 2016.

[8] M. Podda, C. Gerardi, N. Cillara et al., "Antibiotic treatment and appendectomy for uncomplicated acute appendicitis in adults and children," Annals of Surgery, vol. 270, no. 6, pp. 1028-1040, 2019.

[9] D. Papandria, S. D. Goldstein, D. Rhee et al., "Risk of perforation increases with delay in recognition and surgery for acute appendicitis," Journal of Surgical Research, vol. 184, no. 2, pp. 723-729, 2013.

[10] O. N. Farber, G. I. Gomez, A. L. Titan et al., "Impact of COVID-19 on presentation, management, and outcomes of acute care surgery for gallbladder disease and acute appendicitis," World Journal of Gastrointestinal Surgery, vol. 13, no. 8, pp. 859-870, 2021.

[11] P. B. Mehanathan, A. A. Edwards, and T. Robinson, "Experience of a surgeon at the emergency department during COVID-19 pandemic," Annals of Medicine and Surgery, vol. 60, pp. 245-248, 2020.

[12] F. D’Urbano, N. Fabbri, M. K. Radica, E. Rossin, and P. Carcoforo, "Emergency surgery in COVID-19 outbreak: has anything changed? Single center experience," World Journal of Clinical Cases, vol. 8, no. 17, pp. 3691-3696, 2020.

[13] Z. Pogorelić, K. Milanović, A. B. Veršić et al., "Is there an increased incidence of orchiectomy in pediatric patients with acute testicular torsion during COVID-19 pandemic?-A retrospective multicenter study," Journal of Pediatric Urology, vol. 17, no. 4, pp. e1-479, 2021.

[14] Z. Gao, M. Li, H. Zhou et al., "Complicated appendicitis are common during the epidemic period of 2019 novel coronavirus (2019-nCoV)," Asian Journal of Surgery, vol. 43, no. 10, pp. 1002-1005, 2020.
[15] G. Orthopoulos, E. Santone, F. Izzo et al., "Increasing incidence of complicated appendicitis during COVID-19 pandemic," The American Journal of Surgery, vol. 221, no. 5, pp. 1056-1060, 2021.

[16] S. Meriç, T. VartanogluAktokmakyan, M. Tokocin, Y. E. Aktimur, N. A. Hacım, and O. B. Gülcicek, "Comparative analysis of the management of acute appendicitis between the normal period and COVID-19 pandemic," UlusTravmaAcilCerrahiDerg, vol. 27, no. 1, pp. 22-25, 2021, English.

[17] R. Place, J. Lee, and J. Howell, "Rate of pediatric appendiceal perforation at a children's hospital during the COVID-19 pandemic compared with the previous year," JAMA Network Open, vol. 3, no. 12, Article ID e2027948, 2020.

[18] T. D. Zaikos, E. M. Boudiab, E. C. Peshel et al., "Acute appendicitis severity during the early COVID-19 pandemic period," Trauma Surgery \& Acute Care Open, vol. 6, no. 1, Article ID e000809, 2021.

[19] M. Lazzerini, E. Barbi, A. Apicella, F. Marchetti, F. Cardinale, and G. Trobia, "Delayed access or provision of care in Italy resulting from fear of COVID-19," The Lancet Child \& Adolescent Health, vol. 4, no. 5, pp. e10-e11, 2020.

[20] P. Finkelstein, O. Picado, K. Muddasani et al., "A retrospective analysis of the trends in acute appendicitis during the COVID-19 pandemic," Journal of Laparoendoscopic \& Advanced Surgical Techniques, vol. 31, no. 3, pp. 243-246, 2021.

[21] L. Pan, M. Mu, P. Yang et al., "Clinical characteristics of COVID-19 patients with digestive symptoms in hubei, China: a descriptive, cross-sectional, multicenter study," American Journal of Gastroenterology, vol. 115, no. 5, pp. 766-773, 2020.

[22] K. Suwanwongse and N. Shabarek, "Successful conservative management of acute appendicitis in a coronavirus disease 2019 (COVID-19) patient," Cureus, vol. 12, Article ID e7834, 2020.

[23] J. Tankel, A. Keinan, fnm Blich et al., "The decreasing incidence of acute appendicitis during COVID-19: a retrospective multi-centre study," World Journal of Surgery, vol. 44, no. 8, pp. 2458-2463, 2020.

[24] F. Köhler, L. Acar, A. van den Berg et al., "Impact of the COVID-19 pandemic on appendicitis treatment in Germanya population-based analysis," Langenbeck's Archives of Surgery, vol. 406, no. 2, pp. 377-383, 2021.

[25] E. La Pergola, A. Sgrò, F. Rebosio et al., "Appendicitis in children in a large Italian COVID-19 pandemic area," Frontiers in Pediatrics, vol. 8, Article ID 600320, 2020.

[26] M. Aharoni, Y. Barash, Y. Zager et al., "Management of acute appendicitis during the COVID-19 pandemic: a single tertiary center experience," The Israel Medical Association Journal, vol. 23, no. 5, pp. 269-273, 2021.

[27] S. Turanli and G. Kiziltan, "Did the COVID-19 pandemic cause a delay in the diagnosis of acute appendicitis?" World Journal of Surgery, vol. 45, no. 1, pp. 18-22, 2021.

[28] A. W. Wang, J. Prieto, D. S. Ikeda, P. R. Lewis, E. M. Benzer, and J.-M. Van Gent, "Perforated appendicitis: an unintended consequence during the coronavirus-19 pandemic," Military Medicine, vol. 186, no. 1-2, pp. e94-e97, 2021.

[29] J. C. Fisher, S. S. Tomita, H. B. Ginsburg, A. Gordon, D. Walker, and K. A. Kuenzler, "Increase in pediatric perforated appendicitis in the New York city metropolitan region at the epicenter of the COVID-19 outbreak," Annals of Surgery, vol. 273, no. 3, pp. 410-415, 2021.

[30] S. Baral, R. K. Chhetri, and N. Thapa, "Comparison of acute appendicitis before and within lockdown period in COVID19 era: a retrospective study from rural Nepal," PLoS One, vol. 16, no. 1, Article ID e0245137, 2021. 